\title{
Remote Working: A Double-Edged Sword for Workers' Personal and Professional Well-Being
}

\section{Nicolas Gillet*}

QualiPsy EE 1901, Université de Tours, Tours, France

Institut Universitaire de France (IUF)

Tiphaine Huyghebaert-Zouaghi*

C2S EA 6291, Université de Reims Champagne-Ardenne, Reims, France

Stéphanie Austin

LIPROM, Université du Québec à Trois-Rivières, Trois-Rivières, Québec, Canada

Claude Fernet

LIPROM, Université du Québec à Trois-Rivières, Trois-Rivières, Québec, Canada

Alexandre J.S. Morin

Substantive-Methodological Synergy Research Laboratory, Concordia University, Montreal, Québec, Canada

* The first two authors (N. G, \& T. H.-Z.) contributed equally to the preparation of this article, their order was determined at random: Both should be considered first authors.

\section{Corresponding author:}

Nicolas Gillet,

Université de Tours,

Faculté Arts et Sciences Humaines,

Département de psychologie,

3 rue des Tanneurs, 37041 Tours Cedex 1, France

E-mail: nicolas.gillet@univ-tours.fr

This is the prepublication version of the following manuscript:

Gilllet, N., Huyghebaert-Zouaghi, T., Austin, S., Fernet, C., \& Morin, A. J. S. (in press). Remote working: A double-edged sword for workers' personal and professional well-being. Journal of Management \& Organization. Early view. https://doi.org/10.1017/jmo.2021.71

(C) 2022. This paper is not the copy of record and may not exactly replicate the authoritative document published in Journal of Management \& Organization. 


\begin{abstract}
While research suggests that work centrality has a positive effect on work engagement and a negative influence on family satisfaction, these relations may differ as a function of one's work setting (onsite vs. remote working). In the present study, we examined the direct and indirect -through work-family conflict (WFC), family-work conflict (FWC), work-family enrichment (WFE), and family-work enrichment (FWE)- effects of work centrality on work engagement and family satisfaction. We also examined whether these effects of work centrality on work engagement and family satisfaction differed between onsite and remote employees. We used a cross-sectional survey design to test our hypotheses among a total of 432 employees, including 152 always working onsite and 280 working remotely. As expected, our results revealed that work centrality was positively related to work engagement and negatively to family satisfaction. Moreover, the indirect effects of work centrality on work engagement were significantly mediated by WFE, whereas the indirect effects of work centrality on family satisfaction were significantly mediated by FWC, WFE, and FWE. Finally, the relations between work centrality and the outcomes (work engagement and family satisfaction) were stronger among onsite employees than among remote employees. These results revealed that remote working may act as a double-edged sword by buffering the negative effects of work centrality on family satisfaction but also limiting the positive effects of work centrality on work engagement. Organizations and managers should thus consider addressing employees' work centrality and work type in their efforts to promote employees' professional and personal well-being. Keywords: Work centrality; work engagement; family satisfaction; mediation; moderation; workfamily conflict and enrichment; remote working
\end{abstract}


Whereas work occupies a central position in the identity and value system of some employees, it plays a secondary role for other employees (Carr et al., 2008). This phenomenon is captured by the construct of work centrality, which refers to employees' beliefs regarding the importance of work in their own identity (Paullay et al., 1994). Employees with a high level of work centrality tend to display higher levels of identification with their work role relative to other roles (e.g., family role) and to devote a lot of time and energy in their work-related activities (Carr et al., 2008). Research has shown that work centrality, as well as similar beliefs and values, had a significant impact on the way employees manage their work-family interface and on their psychological well-being in and outside of the work setting (e.g., Reb et al., 2018; van Hooff \& van Hooft, 2016).

On the one hand, work centrality tends to be accompanied by a variety of desirable outcomes from the perspective of the employing organizations (e.g., higher levels of work performance and job satisfaction; Mannheim et al., 1997), and might even protect employees against the undesirable effects of work-related stressors (e.g., Hu et al., 2018). On the other hand, employees who consider work as a central part of their life may also experience difficulties in their personal life. Indeed, as they tend to invest a great deal of efforts or resources into their work role, these employees may have fewer resources to allocate to their family life, leading them to experience more difficulties in achieving a satisfactory level of balance between the demands of, and benefits received from, their work and family lives (Greenhaus \& Beutell, 1985). Yet, these possible undesirable effects of work centrality have rarely been investigated ( $\mathrm{Li}$ et al., 2020).

Furthermore, these effects are likely to differ across work contexts. More precisely, the present study considers the possibility that the effects of work centrality may be moderated by the type of work (i.e., whether employees work onsite or remotely). Onsite working refers to work carried out outside of one's house in a formal external workplace or office, whereas remote working allows employees to work outside of a traditional office environment (i.e., working from home). Employees who consider work to be a central part of their life may be more, or less, vulnerable when working remotely because, based on role-identity salience (Thoits, 1992), their work role becomes less salient when enacted outside of a formal workplace. Indeed, remote workers rely on information technology to communicate with other people from their workplace and have very little face-to-face interaction 
with their head office, colleagues, or supervisors (Charalampous et al., 2019). For this reason, the effects of work centrality may become less pronounced for remote employees, leading them in turn to experience lower levels of engagement in their work role but possibly higher levels of satisfaction with their family life than onsite employees experiencing matching levels of work centrality. In the context of the COVID-19 pandemic, which has forced many onsite employees to work remotely, the previously predominantly ignored reality of remote employees has suddenly come to the forefront of organizational considerations regarding how best to support and increase the work engagement and psychological functioning of these employees. For instance, recent reports suggest that employees forced to make the transition to remote work tend to struggle in coordinating their work and family obligations (i.e., to reach successful work-family balance; Hjálmsdóttir \& Bjarnadóttir, 2020), resulting in less adaptive functioning in professional and personal settings (Franken et al., 2021).

The present study was specifically designed to address these two critically important issues (i.e., the possible negative effects of work centrality and how these might differ between remote and onsite employees) by capitalizing on research conducted on the work-family interface (Edwards \& Rothbard, 2000). More precisely, we focus on two critical dimensions of the work-family interface, namely conflict (i.e., when one domain is seen as interfering with the other) and enrichment (i.e., when one domain is seen as benefiting the other) from work to family and from family to work (Greenhaus \& Powell, 2006; Wayne et al., 2017). Moreover, although psychological well-being is a relatively complex multifaceted construct (Morin et al., 2017), the present study considers two specific components of psychological well-being related to employees' functioning in (i.e., work engagement) and out (i.e., family satisfaction) of their work setting, which have both been found to be associated with work centrality (van Hooff \& van Hooft, 2016; Xie et al., 2017) and the work-family interface (Burch, 2020; Carvalho \& Chambel, 2016). Family satisfaction represents one facet of employees' emotional well-being (or hedonic well-being; Ryan \& Deci, 2001) defined as the extent to which individuals are satisfied with their family life (Burch, 2020). In contrast, work engagement represents a facet of employees' positive functioning at work (or eudaimonic well-being; Ryan \& Deci, 2001), and is defined as a positive, fulfilling, and work-related state of mind that is characterized by vigor, dedication, and absorption (Schaufeli et al., 2019). 
More precisely, the present study thus seeks to examine the: (1) direct and indirect effects of work centrality on work engagement and family satisfaction while considering four distinct psychological mechanisms (i.e., mediators), namely work-family conflict (WFC), family-work conflict (FWC), work-family enrichment (WFE), and family-work enrichment (FWE); and (2) how the associations between work centrality, work engagement and family satisfaction differ between onsite and remote employees (see Figure 1). This study is guided by the theoretical perspectives of the work-home resources model (ten Brummelhuis \& Bakker, 2012), control theory (Carver \& Scheier, 1990), and person-environment fit theory (Yang et al., 2008), as well as by various theoretical considerations specific to research on work centrality (e.g., Paullay et al., 1994). The current investigation differs from previous research focusing on work centrality as a moderator in the work-family literature (Carr et al., 2008; Shi et al., 2021). By demonstrating the potential negative effects of employees' work centrality on their well-being as mediated by the effects of work-centrality on various components of the work-family interface, and by considering whether and how these associations differ between employees working remotely or onsite, this research seeks to improve our understanding of the multiple effects of work centrality for employees exposed to different types of work settings. In doing so, we hope to help to further unpack some of the mechanisms involved in the effects of work centrality and work type (remote or onsite). By unpacking these mechanisms, our goal is to provide some practical guidance for organizations seeking to support employees highly value their work role (i.e., work-centered employees) in navigating the specific challenges posed by having to work remotely or onsite in relation to their ability to maintain a satisfactory work-family interface, as well as a satisfactory level of well-being.

\section{Work Centrality and Psychological Well-Being}

Employees characterized by a high level of work centrality anchor a significant part of their identity in their work role, and tend to experience a high sense of commitment to, and connection with, their work role (Mannheim et al., 1997). Accordingly, work-centered employees tend to allocate more of their personal resources (e.g., time and efforts) to the work domain and to be ready to make more personal sacrifices in order to enhance their work performance (Reb et al., 2018). These employees also tend to consider work success as more psychologically rewarding than successes 
occurring in other life domains (e.g., family; Carr et al., 2008). When at work, work-centered employees tend to be more fully engaged with their tasks than other employees (Paullay et al., 1994), due in part to their greater ability to become cognitively and attitudinally immersed in their work (Mannheim et al., 1997). As a result, it is not surprising to note that previous research has reported positive associations between work centrality and work engagement (Bakker et al., 2019; Eldor \& Vigoda-Gadot, 2017), as well as other related constructs such as job satisfaction (Mannheim et al., 1997) or organizational commitment (Jiang \& Johnson, 2018). Being driven to work by more intrinsic motives (Gillet et al., 2017), employees for whom work occupies a more central place in their life also tend to derive pleasure and satisfaction from their work even in the absence of tangible reward (Bagger \& Li, 2012).

Despite these positive work-related outcomes of work centrality, limited research has considered the possible effects of this construct on employee well-being outside of the work setting (e.g., family satisfaction; Xie et al., 2017). Indeed, whereas work-centered employees tend to devote a lot of time, effort, and energy in their work (Carr et al., 2008), their psychological resources available to sustain such an intense investment at work remain limited (Hobfoll, 2011), and may thus become unavailable to support their family life. Moreover, these employees have been reported to feel restless when not at work, and to experience difficulties withdrawing cognitively and emotionally from work during their off-job time (Matthews \& Barnes-Farrell, 2010). In failing to properly stop thinking about work, work-centered employees may even end up creating even more work for themselves, which then requires even higher levels of investment, and which typically leads to feelings of disappointment and frustration among them as well as among their family members (Demsky et al., 2014). In this regard, it is not surprising to note that previous research, albeit limited, has revealed a negative effect of work centrality on family satisfaction (Xie et al., 2017). Based on these considerations, we propose that:

Hypothesis 1 . Work centrality will be positively related to work engagement and negatively related to family satisfaction.

\section{Work Centrality and the Work-Family Interface}

The bidirectional (from work to family as well as from family to work) and dual (conflict and enrichment) nature of the relationship between the work and the family domains is well-established in 
the research literature focusing on the work-family interface (Greenhaus \& Beutell, 1985; Wayne et al., 2017). More specifically: (a) WFC occurs when work responsibilities interfere with employees' ability to meet their family obligations; (b) FWC occurs when family-related demands hinder employees' ability to meet the demands or their work life; (c) WFE occurs when resources gained from the work domain help employees to fulfill family demands; and (d) FWE occurs when familyrelated resources help employees to meet their work-related demands.

Past studies have shown significant effects of work centrality on these four components of the work-family interface (Bennett et al., 2017; Lapierre et al., 2018). To better understand these effects, one has to take into consideration the duality of work centrality as a set of beliefs that can lead to both a decrease (due to their high level of work investment) and an increase (due to their high level of work satisfaction, engagement, and commitment) in employees' resources. Thus, on the one hand, employees for whom work occupies a central place and who consider fulfilling job responsibility as important, tend to spend an excessive amount of time and effort at work at the expense of their family life, thus interfering with their work-life balance, decreasing their ability to allocate some of their personal resources to their family role, and thus increasing their chances of experiencing WFC (Carlson \& Kacmar, 2000). Likewise, work-centered employees, because they tend to expand most of their personal resources at work which they consider to be a central part of their identity, may come to adopt defensive strategies to protect themselves from further loss of resources in other life domains (Hobfoll, 2011). As a result, they are more likely to experience family-related demands as a threat to their work functioning, which is a form of FWC (Cheng et al., 2019; Mansour \& Tremblay, 2016). In addition, when work and family issues conflict with each other, work-centered employees are more likely to consider family responsibility (the less important one) as disturbing and interfering with their work responsibility (the top priority). Given the willingness of work-centered employees to make sacrifice to preserve their work role, these considerations suggest a positive association between work centrality and FWC. Yet, although they may consider their family life as less important, their higher level of dedication to their work does not protect work-centered employees against a higher likelihood of experiencing WFC as a result of their reduced ability to meet family obligations.

However, other perspectives (Bakker et al., 2019; Hobfoll, 2011) suggest that work centrality 
should lead employees to build up, or accumulate, work-related resources as a result of the importance they ascribe to their work (e.g., better health, more positive mood, greater knowledge and skills; Mannheim et al., 1997). As these work-related resources accumulate, they may become available to support them, through both instrumental and affective pathways (Loi et al., 2018), in meeting their family demands (i.e., WFE; Carlson et al., 2019; Grzywacz et al., 2007). Conversely, employees high in work centrality also tend to be more involved in the role that is central to their self-definition (i.e., work), and from which they draw the most satisfaction, than to less central and less satisfying roles (e.g., family; Jiang \& Johnson, 2018), which may in turn limit their true desire to expand work-related resources into the family domain. Finally, when the family domain is considered, research is clearer in showing that higher levels of positive involvement in one's family life tends to be associated with higher levels of FWE (Lapierre et al., 2018). However, because work-centered employees are not able to fully benefit from their family life (e.g., increased positive affect due to close relationships with their spouse and children), they may struggle more in their ability to draw on their family-related resources to enhance their work experience (Greenhaus \& Powell, 2006) and should thus experience lower levels of FWE. In sum, we propose that:

Hypothesis 2. Work centrality will be positively associated with WFC, WFE, and FWC, although the association involving WFE should be weaker than that involving WFC and FWC, and negatively associated with FWE.

\section{The Work-Family Interface and Psychological Well-Being}

Increased levels of attention have recently been allocated to research focusing on the effects of WFE and FWE on employees' well-being in and out of the work context (Heskiau \& McCarthy, 2021; Kacmar et al., 2020). Indeed, according to the affective pathway of the work-family enrichment model (Greenhaus \& Powell, 2006), employees experiencing high levels of WFE gain resources from their work (e.g., self-esteem, sense of accomplishment, motivation, positive affect, vitality), and should come to display higher levels of psychological well-being at work (e.g., work engagement) as a direct result of these additional resources (Carlson et al., 2011). Furthermore, they may also come to adopt more positive work-related attitudes, including higher levels of work engagement, as a way to reciprocate for their positive work experiences (McNall et al., 2010). In addition, beyond the impact 
of these additional resources on employees' work-related life, these resources may also spillover into the personal domain (Greenhaus \& Powell, 2006), allowing them to better meet their family obligations (McNall et al., 2010) and resulting in higher levels of family satisfaction (Carlson et al., 2011). Supporting these propositions, meta-analytic results (Zhang et al., 2018), as well as more recent research results (e.g., Koekemoer et al., 2021), confirm the presence of positive associations between WFE, work engagement and family satisfaction.

Likewise, FWE occurs when resources generated in the family domain do help to improve employees' experience in the work domain. More precisely, when employees develop positive attitudes and feelings toward their family role (i.e., family satisfaction; Zhang et al., 2018), social exchange theory suggests that they may first want to reciprocate with greater positive evaluations of their family role (McNall et al., 2010). However, just like WFE, the resources gained via FWE can also be expected to spillover into the work domain, leading employees to feel more positive and energetic at work (i.e., work engagement; Hobfoll, 2011). Meta-analytic results once again support the presence of positive associations between FWE and family satisfaction (Zhang et al., 2018). Moreover, although a limited number of studies investigated, and supported, the presence of positive associations between FWE and engagement (Timms et al., 2015), Zhang et al.'s (2018) meta-analysis supports the presence of positive associations between FWE and many other indicators of positive functioning at work (e.g., job satisfaction, commitment, performance). Based on the aforementioned considerations, we thus expect that:

Hypothesis 3. WFE and FWE will be associated with higher levels of work engagement and family satisfaction.

Turning our attention to FWC, when employees perceive that their family-related demands hinder their work functioning, they are likely to attribute their struggles at meeting their work-related obligations to their family life (Bagger \& Li, 2012), resulting in a less positive assessment of the latter (i.e., lower family satisfaction). For example, if employees have trouble concentrating at work following a fight with their spouse, they are likely to hold their spouse responsible for their workrelated difficulties. Supporting this proposition, previous studies have supported the negative effects of FWC on family satisfaction (Bagger \& Li, 2012; Michel \& Clark, 2009; Pattusamy \& Jacob, 2017). 
However, when WFC and FWC are jointly considered in research, WFC itself does not share any association with family satisfaction, which can be entirely explained by FWC (Wayne et al., 2004). These domain specific links can be expected to occur because WFC and FWC can be conceptualized as being far more intricately connected to their respective domains, than other types of work- and family-related demands (Netemeyer et al., 1996). Although similar mechanisms could be expected to result in stronger associations between WFC, relative to FWC, and work engagement, these associations do not appear to be independent from FWE and WFE. Indeed, in comparison to demands, even domain-specific resources seem likely to spillover into other domains. In this regard, it is particularly interesting to note that, when WFE and FWE are simultaneously considered, WFC and FWC no longer have a significant effect on work engagement, which appears to be entirely predicted by employees' experience of enrichment (WFE and FWE), particularly at work (WFE) (Boyar \& Mosley, 2007; van Steenbergen et al., 2014). Together, these considerations lead us to propose that:

Hypothesis 4. FWC, but not WFC, will be associated with lower levels of family satisfaction, whereas no association will be found between FWC/WFC and work engagement.

The relations considered in the present study describe a partial mediation pathway according to which: (1) work centrality predicts work engagement and family satisfaction (Hypothesis 1), as well as WFC, WFE, FWC, and FWE (Hypothesis 2); and (2) WFE and FWE predict work engagement and family satisfaction (Hypothesis 3), whereas FWC predicts family satisfaction (Hypothesis 4). In line with past research demonstrating similar indirect effects of work centrality on work behaviors and well-being (Bal \& Kooij, 2011; Blakely et al., 2005), we thus hypothesize the following mediation.

Hypothesis 5. WFE and FWE will partially mediate the effect of work centrality on work engagement, WFE, FWE, and FWC will partially mediate the effect of work centrality on family satisfaction, whereas WFC will not act as a mediator of any of those associations.

\section{The Moderating Role of Working Onsite Versus Remotely}

In addition to the direct effects of work centrality on work engagement and family satisfaction, we also propose that these direct effects of work centrality could differ (i.e., be moderated) between onsite and remote employees. More precisely, based on the person-environment interaction model (Kristof-Brown, 2000), the extent to which work centrality predicts work engagement and family 
satisfaction can be expected to be contingent on contextual variables (e.g., work type).

Employees have different preferences when it comes to managing the boundaries between their work and family domains (Kossek et al., 2012). These preferences range from integration (i.e., employees prefer having no physical, temporal, and behavioral distinction between their work and personal roles) to segmentation (i.e., employees prefer clearly separating their work role from their family role through the creation of impermeable physical, temporal, and behavioral boundaries; Ashforth et al., 2000). Despite these preferences, working remotely facilitates the integration of both roles (Sherman, 2020). This phenomenon may explain the inconsistent findings reported previously regarding the effects of remote working. Indeed, whereas some studies demonstrated desirable effects of remote working on facets of employees' well-being and on components of the work-family interface (Kaduk et al., 2019; Kelliher \& Anderson, 2010), others have shown that remote working could also be linked to detrimental outcomes due to a desire to reciprocate for the increased flexibility afforded to employees by their organization (Chesley, 2010; Shockley et al., 2021).

Due to this lack of consensus regarding the effects of remote versus onsite working on psychological well-being, we rather argue that this characteristic, rather than play a direct role, will moderate the effects of work centrality on professional (i.e., work engagement) and personal (i.e., family satisfaction) well-being. More specifically, we expect remote working to act as a double-edged sword able to reduce (or buffer) the positive effects of work centrality on work engagement and the negative effects of work centrality on family satisfaction.

Work-centered employees consider that their work facilitates their growth and development and plays a central role in their life (van Hooff \& van Hooft, 2016). From the perspective of Carver and Scheier's (1990) control theory, the psychological well-being of work-centered employees can be expected to suffer in a context (i.e., remote working) that limits their ability to work efficiently due to the unavailability of a peace and quiet room to work, to insufficient access to the technologies and support required to support their work, and to the various interruptions caused by their family life. In this context, the normative demands of their family life during their worktime (e.g., childcare-related emergencies at home) may be perceived as a nuisance by work-centered employees who may see these demands as interfering with their ability to meet work requirements and as contributing to drain 
the psychological resources that they should be allocating to their job. As a result, these demands may interfere with the ability of these employees to experience their work in a positive and fulfilling state of mind (i.e., lower work engagement). Furthermore, the otherwise positive effects of work centrality on work engagement typically observed among onsite employees may also be reduced when work is accomplished in a (i.e., remote) setting that makes the work role less salient (Thoits, 1992), and makes it harder to benefit from supportive social interactions with their supervisor and colleagues (Kirk \& Belovics, 2006), known to be positively associated with work engagement (Gillet et al., 2018).

In contrast, the person-environment fit perspective (Yang et al., 2008) suggests that a better fit between individuals' work-related beliefs (such as work centrality) and their work characteristics (such as working onsite) should be associated with higher levels of work engagement (Lu et al., 2014). Generally speaking, this higher level of person-environment fit experienced by work-centered employees working onsite is likely to increase their expectancies of being able to successfully attain their professional goals, leading them to become even more engaged in the pursuit of these goals (van Hooff \& van Hooft, 2016). Likewise, individuals generally display a tendency to maintain clear boundaries around life domains that they see as critical to their self-concept (i.e., the work domain for work-centered individuals), making them more likely to let the demands of their work interfere with their personal life than the reverse (Matthews \& Barnes-Farrell, 2010), which is much easier to do when working onsite. Acknowledging that these propositions ignore the possible moderating role of personal preferences (unrelated to work centrality) and of other types of work characteristics (such as the need to be creative, or to have constant access to resources located in the office) likely to increase or decrease the relevance of working onsite or remotely, we more generally argue that:

Hypothesis 6 . The positive associations between work centrality and work engagement will be stronger among onsite employees and weaker among remote employees.

Turning our attention to family satisfaction, remote working provides any employees with higher levels of autonomy and flexibility relation to the accomplishment of their work activities (Sherman, 2020). For instance, work-centered remote employees tend to feel more in control of when and how they transition between their work and family roles (Kossek et al., 2012). As a result, it might be easier for work-centered remote employees (relative to their onsite peers) to reduce the negative 
spillover effects from their work into the family domain (Golden et al., 2006), allowing them to better fulfill their family responsibilities and thus to maintain higher levels of family satisfaction. Indeed, the fact that work-centered employees consider their family responsibilities to be secondary to their work responsibility does not mean that there are immune to, or uncaring about, their family responsibilities, and working remotely makes it even harder for them to ignore these responsibilities. However, while making these responsibilities more salient, the remote work setting also gives them far more flexibility in meeting these obligations without also having to make work-related sacrifices. In contrast, working onsite is likely to make it easier for work-centered employees to ignore these responsibilities, thus reinforcing their natural tendencies to invest time and energy into their work roles to the detriment of their family roles (Carr et al., 2008; Xie et al., 2017). Yet, ignoring them does not mean that these responsibilities would disappear, simply that they are more likely to be inadequately met. For instance, any work-centered employee may have to pick up their kids after school. For those working onsite, this obligation is likely to mean leaving the office earlier than they might want to, possibly loosing even more time facing rush hours, and having to stay away from their main workstation until the next morning. In contrast, remote employees might simply need to organize their schedule differently to meet this obligation and would be able to go back to work while the kids do their homework, or when they have been put to bed. Furthermore, as noted above, remote work might also help to decrease the saliency of the work-role among work-centered employees (Thoits, 1992), thus reducing the negative spillover of work-related stressors into their personal life (Edwards \& Rothbard, 2000) and making it easier for them to redistribute their resources across domains (Cheng et al., 2019). In contrast, the negative effects of work centrality on family satisfaction might be exacerbated among onsite employees who have to work in a setting that makes their family role less salient (Thoits, 1992). Based on these considerations, we propose that:

Hypothesis 7 . The negative associations between work centrality and family satisfaction will be stronger among onsite workers and weaker among remote workers.

\section{Method}

\section{Participants and Procedure}

Participants were invited to complete an online questionnaire via the Prolific Academic 
crowdsourcing platform. Before completing the questionnaire, participants were provided information on the objectives of the research and were informed that participation was voluntary and confidential and that they could freely withdraw from the project at any time. Participants were compensated $£ 1.75$ for completing the questionnaires (15 minutes).

Recruitment was limited to participants: (1) who lived with a spouse or partner; (2) for whom English was the first language; and (3) who were employed by an organization and who were not selfemployed. The survey also included two questions assessing participants' attention (e.g., "It is important that you pay attention to our survey, please tick strongly disagree"), and one final question verifying "for scientific reasons", if they really worked in an organization. Only respondents who successfully completed all of those verifications were included in the study, leading to 432 participants, including $54.6 \%$ females. Of those participants, 152 mentioned always working onsite, and 280 mentioned working remotely. Participants lived and worked in the UK (74.3\%) or USA $(25.7 \%)$, and $94.9 \%$ held a bachelor degree. They had a mean age of 40.06 years $(S D=10.44)$ and a mean tenure in their current position of 6.27 years $(S D=5.64)$. The majority of the participants held a permanent (93.5\%) full-time (89.4\%) position. Participants mainly worked in the private sector (60.6\%). More precisely, participants worked in non-market services (50.0\%), market services $(35.2 \%)$, industry $(10.0 \%)$, construction $(2.1 \%)$, agriculture $(0.7 \%)$, or other sectors $(2.1 \%)$.

\section{Measures}

Work centrality. Work centrality was measured using a five-item scale (e.g., "Work should be considered central to life rather than family"; $\alpha=.92$ ) developed by Carr et al. (2008). All items were rated on a five-point response scale ranging from "Strongly Disagree" to "Strongly Agree".

WFC and FWC. A ten-item scale developed by Netemeyer et al. (1996) was used to assess participants' levels of WFC (five items; e.g., "The amount of time my job takes up makes it difficult to fulfill family responsibilities"; $\alpha=.96$ ) and FWC (five items; e.g., "I have to put off doing things at work because of demands on my time at home”; $\alpha=.93$ ). All items were rated on a seven-point response scale ranging from "Strongly Disagree" to "Strongly Agree".

WFE and FWE. A six-item scale developed by Kacmar et al. (2014) was used to measure WFE (three items; e.g., "My involvement in my work makes me feel happy and this helps me be a better 
family member; $\alpha=.91$ ) and FWE (three items; e.g., "My involvement in my family helps me acquire skills and this helps me be a better worker; $\alpha=.85$ ). All items were rated on a five-point response scale ranging from "Strongly Disagree" to "Strongly Agree".

Work engagement. Work engagement was assessed using a three-item scale (i.e., "At my work, I feel bursting with energy", "I am enthusiastic about my job", and "I am immersed in my work"; $\alpha=$ .88) developed by Schaufeli et al. (2019). All items were rated on a seven-point response scale ranging from "Never" to "Always".

Family satisfaction. Family satisfaction was measured with a single item (Shimazu et al., 2015) asking workers to report the extent to which they were satisfied with their family life. Responses were made on a four-point scale ranging from "Dissatisfied" to "Satisfied".

\section{Analyses}

We used Mplus 8.5's (Muthén \& Muthén, 2020) robust maximum likelihood (MLR) estimator for all analyses. Due to the online nature of the data collection, there were no missing data. First, we estimated a confirmatory factor analytic (CFA) model encompassing all multi-item constructs considered in the present study, together with participants observed scores reflecting family satisfaction and the type of job (coded 0 for onsite workers and 1 for remote workers) which were simply allowed to correlate with one another and with the other factors. In this model, all multi-item constructs were defined as latent factors from their a priori indicators and allowed to correlate with one another. No cross-loading or correlated uniqueness was included into this model.

Second, this model was converted to our a priori predictive structural equation model (SEM) in which work centrality was specified as having a direct effect on WFC, WFE, FWC, FWE, work engagement, and family satisfaction. In turn, WFC, WFE, FWC, and FWE were specified as having a direct effect on work engagement and family satisfaction. As a result, work centrality (the predictor) was also assumed to have an indirect effect on work engagement and family satisfaction (the outcomes) through WFC, WFE, FWC, and FWE (the mediators). Due to the later testing of latent interactions involving work type (onsite versus remote), this variable was also allowed to predict all mediators and outcomes. We note, however, that none of the observed relations differed between a model including, or excluding, work type as a predictor. 
To verify the adequacy of our CFA and SEM solutions, we relied on goodness-of-fit indices, where values $>0.90$ and 0.95 on the Tucker-Lewis index (TLI) and the comparative fit index (CFI), and values lower than 0.08 and 0.06 on the root mean square error of approximation (RMSEA) were respectively taken to reflect acceptable and excellent levels of fit (Marsh et al., 2005). In addition, the statistical significance of the indirect effects (IE) of work centrality on the outcomes was calculated using bias-corrected bootstrap (10000 bootstrap samples) confidence intervals (CI; Cheung \& Lau, 2008), which indicate statistical significance when the CI excludes 0.

Finally, to test the extent to which the associations between work centrality and the outcomes (i.e., work engagement and family satisfaction) differed (i.e., was moderated) between onsite and remote workers, latent interactions between work type ( 0 : Onsite workers; 1 : Remote workers) and work centrality were estimated with the latent moderated SEM approach (LMS; Klein \& Moosbrugger, 2000) and allowed to predict the outcomes. Significant interactions were then plotted following simple slope analyses conducted by simply recoding the work type variable (1: Onsite workers; 0 : Remote workers) (Marsh et al., 2013).

\section{Results}

The goodness of fit of the CFA $\left(\chi^{2}=470.343, \mathrm{df}=273 ; \mathrm{CFI}=.971 ; \mathrm{TLI}=.965 ;\right.$ and RMSEA $=$ $.041[.035 ; .047])$ and $\operatorname{SEM}\left(\chi^{2}=683.543, \mathrm{df}=280 ; \mathrm{CFI}=.940 ; \mathrm{TLI}=.931 ;\right.$ and $\mathrm{RMSEA}=.058$ $[.052 ; .063])$ solutions was satisfactory, supporting their ability to provide an accurate representation of the data. Parameter estimates from the CFA solution are reported in Table 1 (factor loadings and uniquenesses) and 2 (latent correlations). These results revealed well-defined, reliable, and related but well-differentiated constructs. The parameter estimates related to the predictive part of the SEM solution, as well as those from the subsequent model including latent interactions, are reported in Table 3. These results indicated that work centrality was associated with higher levels of work engagement and with lower levels of family satisfaction, thus supporting Hypothesis 1. Work centrality was also positively associated with WFC, WFE, and FWC, and was negatively associated with FWE, thus supporting Hypothesis 2. WFE was associated with higher levels of work engagement and family satisfaction, whereas FWE shared marginally significant $(\mathrm{p}<.055)$ positive associations with family satisfaction but not with work engagement. These results thus provide partial support for 
Hypothesis 3. However, FWC was negatively related to family satisfaction but not to work engagement, whereas no associations were found between WFC and family satisfaction or work engagement. These results thus support Hypothesis 4. Finally, when considered on its own, work type was not associated with work engagement, family satisfaction, WFC, WFE, and FWE, consistent with its role as a moderator rather than a predictor in our analyses. However, remote workers unexpectedly tended to report higher levels of FWC than onsite workers, suggesting that work type may also act as a direct predictor of FWC, in addition to its hypothesized role as a moderator.

Our analyses also showed that the indirect effects of work centrality on work engagement were significantly mediated by WFE ( $\mathrm{IE}=.197 ; \mathrm{CI}=.094$ to .310$)$, but not by WFC $(\mathrm{IE}=-.001 ; \mathrm{CI}=-.031$ to .031$), \mathrm{FWC}$ (IE $=-.012 ; \mathrm{CI}=-.050$ to .016 ), or FWE (IE $=-.010 ; \mathrm{CI}=-.042$ to .008$)$. Likewise, the indirect effects of work centrality on family satisfaction were significantly mediated by FWC (IE = $.033 ; \mathrm{CI}=-.067$ to -.013$)$, WFE $(\mathrm{IE}=.035 ; \mathrm{CI}=.014$ to .070$)$, and $\mathrm{FWE}(\mathrm{IE}=-.013 ; \mathrm{CI}=-.037$ to .001 ), but not by WFC (IE $=.004 ; \mathrm{CI}=-.015$ to .024$)$. These results partially support Hypothesis 5 .

Finally, the results revealed that work centrality and work type also interacted in the prediction of work engagement and family satisfaction. However, these interactions only resulted in minimal increases in the proportion of explained variance (2\%), although this increase is aligned with the explanatory power of interaction effects typically observed in the social sciences (Marsh et al., 2013). Simple slope analyses are reported in the bottom section of Table 3, and graphically represented in Figures 2 (work engagement) and 3 (family satisfaction). These analyses revealed that the positive effects of work centrality on work engagement were significant among onsite workers but not among remote workers. Moreover, the negative effects of work centrality on family satisfaction were stronger among onsite workers than among remote workers. Interestingly, these results also revealed that among employees characterized by low levels of work centrality, levels of family satisfaction were higher among onsite workers than among remote workers, whereas these levels were higher among remote workers at the other end of the spectrum (i.e., high levels of work centrality). Taken together, these results support Hypotheses 6 and 7.

\section{Discussion}

The present study sought to investigate the direct and indirect (as mediated by various components 
of the work-family interface) associations between work centrality and employees' personal and professional well-being, while considering how these associations might differ as a result of working remotely (versus onsite). Our results supported the presence of direct associations between work centrality and higher levels of work engagement, as well as with lower levels of family satisfaction. Moreover, our results also indicated that the indirect effects of work centrality on work engagement were mediated by WFE, whereas the indirect effects of work centrality on family satisfaction were mediated by FWC, WFE, and FWE. Importantly, we found that the direct associations between work centrality and the outcomes (work engagement and family satisfaction) were stronger among onsite employees than among remote employees.

\section{Theoretical Implications}

Prior research has emphasized the need to further investigate the effects of work centrality, already known to be linked to positive (e.g., high job satisfaction and organizational commitment) and negative (e.g., low marital satisfaction) outcomes (Bagger \& Li, 2012; Carr et al., 2008; Xie et al., 2017). By revealing that higher levels of work centrality tended to be associated with higher levels of work engagement and with lower levels of family satisfaction, the present results support and enrich these previous observations. These associations can be explained by the fact that work centered employees tend to direct more of their arguably limited (Hobfoll, 2011) resources to the work domain (Reb et al., 2018), leaving fewer resources to allocate to support family life.

Indeed, work-centered employees have been reported to be more likely to make personal sacrifices to enhance their work functioning (Reb et al., 2018), to have a tendency to feel restless when not at work, and to experience difficulties withdrawing from work during off-job time (Matthews \& BarnesFarrell, 2010). These characteristics are likely to reduce their ability to fully embrace their family life. As a result, work-centered employees should be more likely to experience WFC (Carlson \& Kacmar, 2000), and to feel the need to protect themselves against the loss of further resources (Hobfoll, 2011) by disengaging from their family life (Cheng et al., 2019), leading them to experience higher levels of FWC. In contrast, they are also likely to gain some additional resources as a result of their high level of work involvement (e.g., higher self-esteem, organization skills, salary), which might in turn help them to fulfill at least some of their family obligations (i.e., higher WFE; Grzywacz et al., 2007). 
However, by being unable to fully benefit from their family life, work centered employees should be less likely to be able to draw on the benefits of their family role to enhance their work functioning (i.e., low FWE; Greenhaus \& Powell, 2006). By demonstrating that work centrality was associated with higher levels of WFC, WFE, and FWC, as well as with lower levels of FWE, the present results fully support these propositions, and suggest that these facets of the work-family interface may contribute to explain the effects of work centrality on work engagement and family satisfaction.

Indeed, when we consider the enrichment facet of the work-family interface, our results first replicated previous observations (Timms et al., 2015; Zhang et al., 2018) by revealing positive associations between WFE and employees' levels of work engagement and family satisfaction. These associations are consistent with the idea that employees able to capitalize on resources gained from their work activities to support their family functioning (i.e., WFE) should be more likely to reciprocate for this positive treatment via higher levels of work engagement (McNall et al., 2010). These employees should also be more likely to be satisfied with their family life, as a result of their greater ability to fulfill their role as a core member of the family (e.g., Carlson et al., 2011).

In contrast, although our results supported our expectations by revealing that FWE was itself marginally related to higher levels of family satisfaction, thus suggesting that the ability to capitalize on one's family resource to enrich one's work role should lead to more positive attitudes toward their family role (Boyar \& Mosley, 2007; Zhang et al., 2018), they also failed to support our hypothesis that FWE should also be related to higher levels of work engagement. However, it remains possible that the effects of FWE on work engagement may only be indirect in nature (Haar et al., 2018). More specifically, resources gained in the family domain may gradually increase one's ability to face the demands of the work domain (Hobfoll, 2011), in turn leading to an increase in the resources gained form the work domain, which themselves should lead to increased levels of work engagement. Alternatively, this unexpected absence of relation between FWE and work engagement could also be related to our simultaneous consideration of WFE, which are both moderately correlated with one another $(r=.534)$. Given that WFE is itself strongly related to work engagement (e.g., Lapierre et al., 2018) and that multivariate analyses focus on the unique contribution of each predictor beyond what it shares with the other, it is possible that the positive effects of WFE observed in this study might have 
contribute to obscure those of FWE, while also suggesting that the role played by FWE might be smaller in magnitude than those of WFE. It would be interesting for future research to devote more attention to unpacking the mechanisms involved in unique and combined effects of WFE and FWE, while also considering a broader range of outcomes and measures (e.g., spouses' ratings of FWE).

Turning our attention to the conflict facet of the work-family interface, our results first supported our expectations and previous results (Michel \& Clark, 2009; Wayne et al., 2004) by revealing negative associations between FWC and family satisfaction. This observation is consistent with the idea that when employees' family life interferes with their work life, their level of satisfaction with this family life tends to decrease (Bagger \& Li, 2012). In contrast, and failing to support our expectations, our results indicated that neither FWC nor WFC were related to employees' levels of work engagement, and that WFC itself was also unrelated to family satisfaction. Interestingly, other research has similarly demonstrated that, when WFC and FWC are jointly considered, WFC no longer share associations with family satisfaction, because decreases in family satisfaction tend to be more directly explained by FWC (Wayne et al., 2004). From the same perspective, our results suggest that, when all four facets of the work-family interface (WFE, FWE, WFC, and FWC) are jointly considered, the enrichment facets seem to play a far greater explanatory power than the conflict facets (Boyar \& Mosley, 2007; van Steenbergen et al., 2014). Clearly, future research will be needed to replicate the present results, and investigate the specific mechanisms via which these four facets jointly influence employees psychological functioning in both of these critical life domains.

When the whole explanatory chain of association was considered, our results further indicated that work centrality also had indirect effects on work engagement through WFE, as well as indirect effects on family satisfaction through FWC, WFE, and FWE. These results are congruent with previous results demonstrating the influence of work centrality on various outcomes via the work-family interface (Bagger et al., 2014). However, although some variables related to the work-family interface may explain the impact of work centrality on work engagement and family satisfaction, it is noteworthy that the mediating effects found in the previous research where only partial, as work centrality also shared direct associations with these outcomes. Because our results highlight the importance of examining competing mediating processes, future investigations could consider 
additional explanatory mechanisms such as work recovery experiences (e.g., relaxation), rumination, problem-solving pondering, and sleep quality (Bennett et al., 2016; Chawla et al., 2020).

Finally, when considering how the implications of work centrality differed between onsite and remote employees, our results revealed that the direct and indirect effects of work centrality were all substantially more pronounced among onsite workers than among remote workers, for whom these effects were smaller (family satisfaction) or not statistically significant (work engagement). Because remote working blurs work-centered employees' traditional points of reference, it possibly makes their work-centered identity less relevant to their work engagement. In this context, their work engagement may come to depend more importantly on socio-environmental aspects of their work life, such as on the ability of their work environment's ability to nurture their work-centered identity (e.g., performance management: Aguinis \& Pierce, 2008; supportive behaviors from one's supervisor: Huyghebaert-Zouaghi et al., 2021). Conversely, when work-centered employees work onsite, their work-related identity can become anchored in a specific location (i.e., their office), increasing their feelings of connection with their work role, resulting in higher levels of work engagement (Lu et al., 2014). These findings suggest that remote working may, generally, be detrimental for work-centered employees' work engagement, as it does not offer them a clear physical connection and a clear set of protective boundaries to fully embrace their work role. Rather, remote working may represent a specific job demand (an organizational aspect of the job requiring sustained psychological energy) associated with lower levels of work engagement for those employees (Bakker \& Demerouti, 2007). Our results also revealed that remote workers displayed higher levels of FWC that onsite workers. This observation is aligned with previous results revealing that interference between the family and work domains is one of the main challenges for remote workers (Wang et al., 2021). Indeed, when working remotely, employees face more interruptions and distractions from family members (e.g., childcare-related emergencies at home), which may have negative effects on their work effectiveness.

However, beyond these generic considerations, it is important to keep in mind that a variety of personal preferences and work-related characteristics are also likely to moderate these associations by increasing or decreasing the benefits of working remotely or onsite. For instance, programmers and other types of creative workers can typically do their job very efficiently in a remote setting. 
Likewise, some types of consultants and salesperson may be on the road often enough to belong to a completely distinct type of classification (i.e., neither remote, nor onsite). Similarly, workers may also vary in their personal working preferences, so that some may prefer the flexibility and relative isolation that comes from working remotely, whereas other may thrive on the social connection afforded by working onsite. Alternatively, the family context itself could play a role in these associations and preferences (i.e., living alone or living with young children). Future research is thus needed to consider the role played by these characteristics in the observed associations.

In contrast, when family satisfaction is considered, working remotely may help work-centered employees to reduce the negative spillover effects from their work into the family domain, resulting in less detrimental effects on their family satisfaction (Golden et al., 2006). In contrast, when workcentered employees work onsite, their family role becomes less salient (Thoits, 1992), thus accentuating their tendency to devote a lot of time and energy to work and reducing their family satisfaction (Xie et al., 2017). This interpretation is also aligned with the observation that among highly work-centered individuals, onsite employees tend to be less satisfied with their family life than remote employees, whereas an opposite pattern of differences is observed among employees characterized by low levels of work centrality. As previously mentioned, this suggests that the effects of work characteristics may differ as a function of individual beliefs (Yang et al., 2008). More generally, our findings highlight a contingency perspective that help to unpack several pathways though which work centrality may differently influence employees' work and family lives. In this regard, our results indicate, as expected, that remote working seems to act as a double-edged sword for work-centered employees by buffering the negative effects of work centrality on family satisfaction but also limiting the positive effects of work centrality on work engagement.

\section{Limitations and Research Perspectives}

When considering our results, some limitations have to be considered. First, although shared method biases are unlikely to play a role in multivariate analyses (as demonstrated mathematically by Siemsen et al., 2010), the fact that this study relied solely on self-report measures increases the risk of other forms of social desirability and self-report biases. In this regard, it also important to note that, as recommended by Podsakoff et al. (2003), we relied on several additional procedures to further reduce 
the risks associated with this type of methodological design: Protecting and ensuring respondent anonymity, reducing evaluation apprehension (e.g., by assuring respondents that there were no right or wrong answers, and that they should be as honest as possible without any risk of judgment), randomly counterbalancing the order of appearance of the questions, and avoiding item ambiguity by keeping questions simple, specific, and concise. However, to further alleviate these concerns related to self-reported measures, it would be interesting for future studies to consider the incorporation of objective measures (e.g., organizational data on work performance, biological measures of psychophysiological activation) and informant ratings of employees' functioning (e.g., colleagues, supervisors, spouse). Second, we relied on a binary variable (onsite vs. remote working) to measure work type. Yet, remote working arrangements can vary greatly across employees (e.g., fully or partially remote), just like the frequency of remote working might vary (Allen et al. 2015). For instance, in their meta-analysis, Gajendran and Harrison (2007) found that remote workers' relationships with their colleagues only suffered if they worked remotely three or more days each week. Given that remote working is rarely an all-or-nothing work practice, future research should consider the role played by various facets of remote working.

Third, although variables were considered as predictors (i.e., work centrality), mediators (i.e., WFC, FWC, WFE, and FWE), or outcomes (i.e., work engagement and family satisfaction) based on theoretical grounds (Carlson et al., 2011; Carr et al., 2008), our cross-sectional design makes it impossible to confirm the directionality of these associations. It would therefore be fruitful for future studies to explore the issue of directionality through the reliance on longitudinal research designs. For instance, and although our consideration of the work context (onsite or remote) as a moderator of the effects of work centrality is consistent with the trait activation perspective (Tett et al., 2021), a more complete trait-activation perspective suggests that work centrality might also act as a moderator for the effects of employees' job involvement on their work-family interface and well-being. Fourth, the present study was conducted solely among employees working in the UK or USA. Further research is thus needed to generalize the current results in different countries, languages, and cultures. Finally, work centrality was the only individual dimension of interest in our research. Yet, it would be interesting to examine how other personal resources (e.g., psychological capital, self-efficacy) as well 
as hindrance (e.g., role conflict, overload, and ambiguity) and challenge (e.g., role responsibility and complexity) demands relate to employees' work-family interface and well-being, and their interplay with work setting (i.e., remote and onsite working). Moreover, although we relied on theory and research to explain the psychological mechanisms likely to be involved in the effects of work centrality, these hypothetical mechanisms were not measured in this study. It is thus impossible to clearly understand the mechanisms involved in the effects of work centrality, or even to exclude the possibility that these associations may in fact reflect the main effects of these other variables (e.g., job involvement). Once again, longitudinal research would be needed to better unpack the mechanisms underlying the observed associations.

\section{Practical Implications}

Modern society, organizations, and individuals tend to value heavy work investment (Schaufeli et al., 2009). Yet, our findings highlight the need to consider reducing employees' work centrality in order to decrease their likelihood of experiencing conflicts between the work and the family domains (WFC and FWC), in turn leading to increases in family satisfaction. Although family satisfaction, in and of itself, might be of limited interest for organizations, it is important to consider the multiple benefits of family support for employees (Pattusamy \& Jacob, 2017), as well as the fact that family problems often tend to spread into the work domain (Greenhaus \& Beutell, 1985). Moreover, the present results indicate that work centrality itself tends to decrease the likelihood of positive transfers of resources from the family to the work domain (FWE). Possible interventions include changes designed to reduce workload sustainably, which might help decrease work centrality in the long run. Among possible ways to achieve this goal, work centrality prevention could be encouraged at the organizational level (e.g., stating clear segmentation norms and encouraging balanced and healthier lifestyles; Kreiner et al., 2006), but also at the individual level (e.g., seeking counseling to develop new habits and replace one's old malfunctioning behaviors; Van Gordon et al., 2017).

However, caution is needed in relation to the implementation of interventions seeking to reduce employees' work centrality, as this individual belief also caries benefits in terms of WFE and work engagement. Thus, rather than directly acting on the reduction (or the promotion) of work centrality, it might be useful to encourage more efficient work recovery processes among work-centered employees, in 
order to protect their well-being and facilitate interactions between their work and family roles (Demsky et al., 2014). Efficient ways to achieve work recovery can be developed and trained, and approaches to successfully train work recovery have proved to be efficient in previous studies. For instance, participants involved in a recovery training program (e.g., time management techniques, self-reflection) were characterized by better recovery experiences (e.g., relaxation) and higher levels of sleep quality after the training, in comparison to those not involved in this training (Hahn et al., 2011). Mindfulness-based interventions are also useful to increase recovery during off-job time (Hülsheger et al., 2015).

In addition, in the context of the COVID-19 pandemic in which numerous workers have had to start working remotely, our results have great practical significance. More precisely, they suggest that, for remote working to be maximally efficient for most employees (e.g., high work engagement and family satisfaction), organizations could train managers on the best practices to manage remote workers, as remote working comes with new communication and coordination challenges (Shockley et al., 2021). For instance, research based on self-determination theory (Ryan \& Deci, 2017) has shown the importance of managers' interpersonal behaviors which help to nurture employees' psychological needs for autonomy, competence, and relatedness (e.g., Huyghebaert-Zouaghi et al., 2021). While the need for competence is unlikely to be importantly modified (as long as proper resources and support remains available) by remote work, working remotely is likely to interfere substantially with the need for relatedness, thus creating new challenges in how to maintain positive work-related socialization experiences likely to ensure the provision of adequate levels of social support. Furthermore, while remote working could constitute a fertile ground to promote employees' autonomy (Sherman, 2020) and for managers to encourage subordinates' selfinitiation (autonomy support), managers' mistrust toward their teleworking subordinates (Cascio, 1999) could take the form of compensatory controlling behaviors (autonomy thwarting). In this regard, recent research suggests that managers ought to reconsider how they traditionally supervise their subordinates (Kniffin et al., 2020). Indeed, as remote settings makes it "difficult, if not impossible to monitor or micromanage processes, leaders must focus instead on results" (Offstein et al., 2010, p. 36). Therefore, though performance-based management has proven to be beneficial in general work settings (Pritchard et al., 2008), it could be of particular relevance in remote working settings (Mahler, 2012). Finally, as suggested by Hammer et al. (2011), supervisors should enact family-supportive supervisory behaviors 
toward their subordinates working remotely, for instance by listening and showing care for remote workers' work-family challenges.

\section{References}

Aguinis, H., \& Pierce, C.A. (2008). Enhancing the relevance of organizational behavior by embracing performance management research. Journal of Organizational Behavior, 29, 139-145.

Allen, T.D., Golden, T.D., \& Shockley, K.M. (2015). How effective is telecommuting? Assessing the status of our scientific findings. Psychological Science in the Public Interest, 16, 40-68.

Ashforth, B.E., Kreiner, G.E., \& Fugate, M. (2000). All in a day's work: Boundaries and micro role transitions. The Academy of Management Review, 25, 472-491.

Bagger, J., \& Li, A. (2012). Being important matters: The impact of work and family centralities on the family-to-work conflict-satisfaction relationship. Human Relations, 65, 473-500.

Bagger, J., Reb, J., \& Li, A. (2014). Anticipated regret in time-based work-family conflict. Journal of Managerial Psychology, 29, 304-320.

Bakker, A.B., \& Demerouti, E. (2007). The Job Demands-Resources model: State of the art. Journal of Managerial Psychology, 22, 309-328.

Bakker, A.B., Du, D., \& Derks, D. (2019). Major life events in family life, work engagement, and performance: A test of the work-home resources model. International Journal of Stress Management, 26, 238-249.

Bal, P.M., \& Kooij, D. (2011). The relations between work centrality, psychological contracts, and job attitudes. European Journal of Work and Organizational Psychology, 20, 497-523.

Bennett, A.A., Gabriel, A.S., Calderwood, C., Dahling, J.J., \& Trougakos, J.P. (2016). Better together? Examining profiles of employee recovery experiences. Journal of Applied Psychology, 101, 1635-1654.

Bennett, M.M., Beehr, T.A., \& Ivanitskaya, L.V. (2017). Work-family conflict: Differences across generations and life cycles. Journal of Managerial Psychology, 32, 314-332.

Blakely, G.L., Srivastava, A., \& Moorman, R.H. (2005). The effects of nationality, work role centrality, and work locus of control on role definitions of OCB. Journal of Leadership \& Organizational Studies, 12, 103-117.

Boyar, S.L., \& Mosley, D.C., Jr. (2007). The relationship between core self-evaluations and work and 
family satisfaction: The mediating role of work-family conflict and facilitation. Journal of Vocational Behavior, 71, 265-281.

Burch, T. (2020). All in the family: The link between couple-level work-family conflict and family satisfaction and its impact on the composition of the family over time. Journal of Business and Psychology, 35, 593-607.

Carlson, D.S., \& Kacmar, K.M. (2000). Work-family conflict in the organization: Do life role values make a difference? Journal of Management, 26, 1031-1054.

Carlson, D.S., Grzywacz, J.G., Ferguson, M., Hunter, E.M., Clinch, C.R., \& Arcury, T.A. (2011). Health and turnover of working mothers after childbirth via the work-family interface: An analysis across time. Journal of Applied Psychology, 96, 1045-1054.

Carr, J.C., Boyar, S.L., \& Gregory, B.T. (2008). The moderating effect of work-family centrality on workfamily conflict, organizational attitudes, and turnover behavior. Journal of Management, 34, 244-262.

Carvalho, V.S., \& Chambel, M.J. (2016). Work-to-family enrichment and conflict profiles: Job characteristics and employees' well-being. The Spanish Journal of Psychology, 19, Article E65.

Carver, C.S., \& Scheier, M.F. (1990). Origins and functions of positive and negative affect: A controlprocess view. Psychological Review, 97, 19-35.

Cascio, W.F. (1999). Virtual workplaces: Implications for organizational behavior. In C.L. Cooper \& D.M. Rousseau (Eds.), Trends in organizational behavior, Vol. 6. The virtual organization (pp. 114). John Wiley \& Sons Ltd.

Charalampous, M., Grant, C.A., Tramontano, C., \& Michailidis, E. (2019). Systematically reviewing remote e-workers' well-being at work: A multidimensional approach. European Journal of Work and Organizational Psychology, 28, 51-73.

Chawla, N., MacGowan, R.L., Gabriel, A.S., \& Podsakoff, N.P. (2020). Unplugging or staying connected? Examining the nature, antecedents, and consequences of profiles of daily recovery experiences. Journal of Applied Psychology, 105, 19-39.

Cheng, B., Zhou, X., \& Guo, G. (2019). Family-to-work spillover effects of family incivility on employee sabotage in the service industry. International Journal of Conflict Management, 30, $270-287$.

Chesley, N. (2010). Technology use and employee assessments of work effectiveness, workload, and 
pace of life. Information, Communication \& Society, 13, 485-514.

Cheung, G.W., \& Lau, R.S. (2008). Testing mediation and suppression effects of latent variables: Bootstrapping with structural equation models. Organizational Research Methods, 11, 296-325.

Demsky, C.A., Ellis, A.M., \& Fritz, C. (2014). Shrugging it off: Does psychological detachment from work mediate the relationship between workplace aggression and work-family conflict? Journal of Occupational Health Psychology, 19, 195-205.

Edwards, J.R., \& Rothbard, N.P. (2000). Mechanisms linking work and family: Clarifying the relationship between work and family constructs. Academy of Management Review, 25, 178-199.

Eldor, L., \& Vigoda-Gadot, E. (2017). The nature of employee engagement: Rethinking the employeeorganization relationship. International Journal of Human Resource Management, 28, 526-552.

Franken, E., Bentley, T., Shafaei, A., Farr-Wharton, B., Onnis, L., \& Omari, M. (2021). Forced flexibility and remote working: Opportunities and challenges in the new normal. Journal of Management \& Organization. Advance online publication. https://doi.org/10.1017/jmo.2021.40

Gajendran, R.S., \& Harrison, D.A. (2007). The good, the bad, and the unknown about telecommuting: Meta-analysis of psychological mediators and individual consequences. Journal of Applied Psychology, 92, 1524-1541.

Gillet, N., Morin, A.J.S., Cougot, B., \& Gagné, M. (2017). Workaholism profiles: Associations with determinants, correlates, and outcomes. Journal of Occupational and Organizational Psychology, $90,559-586$.

Gillet, N., Morin, A.J.S., Sandrin, E., \& Houle, S.A. (2018). Investigating the combined effects of workaholism and work engagement: A substantive-methodological synergy of variable-centered and person-centered methodologies. Journal of Vocational Behavior, 109, 54-77.

Golden, T.D., Veiga, J.F., \& Simsek, Z. (2006). Telecommuting's differential impact on work-family conflict: Is there no place like home? Journal of Applied Psychology, 91, 1340-1350.

Greenhaus, J.H., \& Beutell, N.J. (1985). Sources and conflict between work and family roles. The Academy of Management Review, 10, 76-88.

Greenhaus, J.H., \& Powell, G.N. (2006). When work and family are allies: A theory of work-family enrichment. The Academy of Management Review, 31, 72-92. 
Grzywacz, J.G., Carlson, D.S., Kacmar, K., \& Wayne, J. (2007). A multi-level perspective on the synergies between work and family. Journal of Occupational \& Organizational Psychology, 80, 559-574.

Haar, J.M., Roche, M., \& ten Brummelhuis, L. (2018). A daily diary study of work-life balance in managers: Utilizing a daily process model. International Journal of Human Resource Management, 29, 2659-2681.

Hahn, V.C., Binnewies, C., Sonnentag, S., \& Mojza, E.J. (2011). Learning how to recover from job stress: Effects of a recovery training program on recovery, recovery-related self-efficacy, and wellbeing. Journal of Occupational Health Psychology, 16, 202-216.

Hammer, L.B., Kossek, E.E., Anger, W.K., Bodner, T., \& Zimmerman, K.L. (2011). Clarifying workfamily intervention processes: The roles of work-family conflict and family-supportive supervisor behaviors. Journal of Applied Psychology, 96, 134-150.

Heskiau, R., \& McCarthy, J.M. (2021). A work-family enrichment intervention: Transferring resources across life domains. Journal of Applied Psychology. Early view. doi 10.1037/ap10000833

Hjálmsdóttir, A., \& Bjarnadóttir, V.S. (2020). "i have turned into a foreman here at home”: Families and work-life balance in times of covid- 19 in a gender equality paradise. Gender, Work and Organization. Advance online publication.

Hobfoll, S.E. (2011). Conservation of resource caravans and engaged settings. Journal of Occupational and Organizational Psychology, 84, 116-122.

Hu, S., Zhong, Z., Zhang, J., \& Zheng, X. (2018). Cognitive flexibility and advice network centrality: The moderating role of self-monitoring. Frontiers in Psychology, 9, Article 1947.

Hülsheger, U.R., Feinholdt, A., \& Nübold, A. (2015). A low- dose mindfulness intervention and recovery from work: Effects on psychological detachment, sleep quality, and sleep duration. Journal of Occupational and Organizational Psychology, 88, 464-489.

Huyghebaert-Zouaghi, T., Ntoumanis, N., Berjot, S., \& Gillet, N. (2021). Advancing the conceptualization and measurement of psychological need states: A $3 \times 3$ model based on selfdetermination theory. Journal of Career Assessment. Early view. doi 10.1177/1069072720978792

Jiang, L., \& Johnson, M.J. (2018). Meaningful work and affective commitment: A moderated mediation model of positive work reflection and work centrality. Journal of Business and 
Psychology, 33, 545-558.

Kacmar, K.M., Andrews, M.C., Valle, M., Tillman, C.J., \& Clifton, C. (2020). The interactive effects of role overload and resilience on family-work enrichment and associated outcomes. The Journal of Social Psychology, 160, 688-701.

Kacmar, K.M., Crawford, W.S., Carlson, D.S., Ferguson, M., \& Whitten, D. (2014). A short and valid measure of work-family enrichment. Journal of Occupational Health Psychology, 19, 32-45.

Kaduk, A., Genadek, K., Kelly, E.L., \& Moen, P. (2019). Involuntary vs. Voluntary flexible work: Insights for scholars and stakeholders. Community, Work \& Family, 22, 412-442.

Kelliher, C., \& Anderson, D. (2010). Doing more with less? Flexible working practices and the intensification of work. Human Relations, 63, 83-106.

Kirk, J., \& Belovics, R. (2006). Making e-working work. Journal of Employment Counseling, 43, 39-46.

Klein, A.G., \& Moosbrugger, H. (2000). Maximum likelihood estimation of latent interaction effects with the LMS method. Psychometrika, 65, 457-474.

Kniffin, K.M., Narayanan, J., Anseel, F., Antonakis, J., Ashford, S.P., Bakker, A.B., Bamberger, P., Bapuji, H., Bhave, D.P., Choi, V.K., Creary, S.J., Demerouti, E., Flynn, F.J., Gelfand, M.J., Greer, L.L., Johns, G., Kesebir, S., Klein, P.G., Lee, S.Y., ... Vugt, M. v. (2021). COVID-19 and the workplace: Implications, issues, and insights for future research and action. American Psychologist, 76, 63-77.

Koekemoer, E., Olckers, C., \& Nel, C. (2021). Work-family enrichment, job satisfaction, and work engagement: The mediating role of subjective career success. Australian Journal of Psychology. Early view. doi: 10.1111/ajpy.12290

Kossek, E.E., Ruderman, M.N., Braddy, P.W., \& Hannum, K.M. (2012). Work-nonwork boundary management profiles: A person-centered approach. Journal of Vocational Behavior, 81, 112-128.

Kreiner, G.E., Hollensbe, E.C., \& Sheep, M.L. (2006). Where is the "me" among the "we"? Identity work and the search for optimal balance. Academy of Management Journal, 49, 1031-1057.

Kristof-Brown, A.L. (2000). Perceived applicant fit: Distinguishing between recruiters' perceptions of person-job and person-organization fit. Personnel Psychology, 53, 643-671.

Lapierre, L.M., Li, Y., Kwan, H.K., Greenhaus, J.H., DiRenzo, M.S., \& Shao, P. (2018). A meta- analysis of the antecedents of work-family enrichment. Journal of Organizational Behavior, 
$39,385-401$.

Li, V., Jiang, L., \& Xu, X. (V.). (2020). From workplace mistreatment to job insecurity: The moderating effect of work centrality. Stress and Health, 36, 249-263.

Loi, R., Xu, A.J., Chow, C.W.C., \& Kwok, J.M.L. (2018). Customer misbehavior and store managers' work- to- family enrichment: The moderated mediation effect of work meaningfulness and organizational affective commitment. Human Resource Management, 57, 1039-1048.

Lu, C.-q., Wang, H.-j., Lu, J.-j., Du, D.-y., \& Bakker, A B. (2014). Does work engagement increase personjob fit? The role of job crafting and job insecurity. Journal of Vocational Behavior, 84, 142-152.

Mahler, J. (2012). The telework divide: Managerial and personnel challenges of telework. Review of Public Personnel Administration, 32, 407-418.

Mannheim, B., Baruch, Y., \& Tal, J. (1997). Alternative models for antecedents and outcomes of work centrality and job satisfaction of high-tech personnel. Human Relations, 50, 1537-1562.

Mansour, S., \& Tremblay, D.-G. (2016). Workload, generic and work-family specific social supports and job stress: Mediating role of work-family and family-work conflict. International Journal of Contemporary Hospitality Management, 28, 1778-1804.

Marsh, H.W., Hau, K.-T., \& Grayson, D. (2005). Goodness of fit in structural equation models. In A. Maydeu-Olivares \& J.J. McArdle (Eds.), Contemporary psychometrics (pp. 275-340). Erlbaum.

Marsh, H.W., Hau, K.-T., Wen, Z., Nagengast, B., \& Morin, A.J.S. (2013). Moderation. In T.D. Little (Ed.), The Oxford handbook of quantitative methods (pp. 361-386). Oxford University Press.

Matthews, R.A., \& Barnes-Farrell, J.L. (2010). Development and initial evaluation of an enhanced measure of boundary flexibility for the work and family domains. Journal of Occupational Health Psychology, 15, 330-346.

McNall, L.A., Nicklin, J.M., \& Masuda, A.D. (2010). A meta-analytic review of the consequences associated with work-family enrichment. Journal of Business and Psychology, 25, 381-396.

Michel, J.S., \& Clark, M. (2009). Has it been affect all along? A test of work-to-family and family-to-work models of conflict, enrichment, and satisfaction. Personality \& Individual Differences, 47, 163-168.

Morin, A.J.S., Boudrias, J.-S., Marsh, H.W., McInerney, D.M., Dagenais-Desmarais, V., Madore, I., \& Litalien, D. (2017). Complementary variable- and person-centered approaches to the 
dimensionality of psychometric constructs: Application to psychological wellbeing at work. Journal of Business and Psychology, 32, 395-419.

Muthén, L.K., \& Muthén, B. (2020). Mplus user's guide. Muthén \& Muthén.

Netemeyer, R.G., Boles, J.S., \& McMurrian, R. (1996). Development and validation of work-family conflict and family-work conflict scales. Journal of Applied Psychology, 81, 400-410.

Offstein, E., Morwick, J., \& Koskinen, L. (2010). Making telework work: Leading people and leveraging technology for competitive advantage. Strategic HR Review, 9, 32-37.

Pattusamy, M., \& Jacob, J. (2017). The mediating role of family-to-work conflict and work-family balance in the relationship between family support and family satisfaction: A three path mediation approach. Current Psychology, 36, 812-822.

Paullay, I.M., Alliger, G.M., \& Stone-Romero, E.F. (1994). Construct validation of two instruments designed to measure job involvement and work centrality. Journal of Applied Psychology, 79, 224-228.

Podsakoff, P.M., MacKenzie, S.B., Lee, J.-Y., \& Podsakoff, N.P. (2003). Common method biases in behavioral research: A critical review of the literature and recommended remedies. Journal of Applied Psychology, 88, 879-903.

Pritchard, R.D., Harrell, M.M., DiazGranados, D., \& Guzman, M.J. (2008). The productivity measurement and enhancement system: A meta-analysis. Journal of Applied Psychology, 93, 540-567.

Reb, J., Li, A., \& Bagger, J. (2018). Decoy effect, anticipated regret, and preferences for work-family benefits. Journal of Occupational and Organizational Psychology, 91, 441-464.

Ryan, R.M., \& Deci, E.L. (2001). On happiness and human potentials: A review of research on hedonic and eudaimonic well-being. Annual Review of Psychology, 52, 141-166.

Ryan, R.M., \& Deci, E.L. (2017). Self-determination theory: Basic psychological needs in motivation, development, and wellness. Guilford.

Schaufeli, W.B., Shimazu, A., \& Taris, T.W. (2009). Being driven to work excessively hard: The evaluation of a two-factor measure of workaholism in the Netherlands and Japan. Cross-Cultural Research, 43, 320-348.

Schaufeli, W.B., Shimazu, A., Hakanen, J., Salanova, M., \& De Witte, H. (2019). An ultra-short measure for work engagement: The UWES-3 validation across five countries. European Journal of 
Psychological Assessment, 35, 577-591.

Sherman, E.L. (2020). Discretionary remote working helps mothers without harming non-mothers:

Evidence from a field experiment. Management Science, 66, 1351-1374.

Shi, Y., Zhang, H., Xie, J., \& Ma, H. (2021). Work-related use of information and communication technologies after hours and focus on opportunities: The moderating role of work-family centrality. Current Psychology, 40, 639-646.

Shimazu, A., Schaufeli, W.B., Kamiyama, K., \& Kawakami, N. (2015). Workaholism vs. work engagement: The two different predictors of future well-being and performance. International Journal of Behavioral Medicine, 22, 18-23.

Shockley, K.M., Clark, M.A., Dodd, H., \& King, E.B. (2021). Work-family strategies during COVID19: Examining gender dynamics among dual-earner couples with young children. Journal of Applied Psychology, 106, 15-28.

Siemsen, E., Roth, A., \& Oliveira, P. (2010). Common method bias in regression models with linear, quadratic, and interaction effects. Organizational Research Methods, 13, 456-476.

ten Brummelhuis, L.L., \& Bakker, A.B. (2012). A resource perspective on the work-home interface: The work-home resources model. American Psychologist, 67, 545-556.

Tett, R.P., Toich, M.J., \& Ozkum, S.B. (2021). Trait activation theory: A review of the literature and applications to five lines of personality dynamics research. Annual Review of Organizational Psychology and Organizational Behavior, 8, 199-233.

Thoits, P.A. (1992). Identity structures and psychological well-being: Gender and marital status comparisons. Social Psychology Quarterly, 55, 236-256.

Timms, C., Brough, P., O'Driscoll, M., Kalliath, T., Siu, O.- L., Sit, C., \& Lo, D. (2015). Positive pathways to engaging workers: Work-family enrichment as a predictor of work engagement. Asia Pacific Journal of Human Resources, 53, 490-510.

Van Gordon, W., Shonin, E., Dunn, T.J., Garcia-Campayo, J., Demarzo, M.M.P., \& Griffiths, M.D. (2017). Meditation awareness training for the treatment of workaholism: A controlled trial. Journal of Behavioral Addictions, 6, 212-220.

van Hooff, M.L.M., \& van Hooft, E.A.J. (2016). Work-related boredom and depressed mood from a 
daily perspective: The moderating roles of work centrality and need satisfaction. Work \& Stress, $30,209-227$.

van Steenbergen, E.F., Kluwer, E.S., \& Karney, B.R. (2014). Work-family enrichment, work-family conflict, and marital satisfaction. Journal of Occupational Health Psychology, 19, 182-194.

Wang, B., Liu, Y., Qian, J., \& Parker, S.K. (2021). Achieving effective remote working during the COVID- 19 pandemic: A work design perspective. Applied Psychology: An International Review, 70, 16-59.

Wayne, J.H., Butts, M.M., Casper, W.J., \& Allen, T.D. (2017). In search of balance: A conceptual and empirical integration of multiple meanings of work-family balance. Personnel Psychology, 70, 167-210.

Wayne, J.H., Musisca, N., \& Fleeson, W. (2004). Considering the role of personality in the workfamily experience: Relationships of the big five to work-family conflict and facilitation. Journal of Vocational Behavior, 64, 108-130.

Xie, J., Shi, Y., \& Ma, H. (2017). Relationship between similarity in work-family centrality and marital satisfaction among dual-earner couples. Personality and Individual Differences, 113, 103-108.

Yang, L.-Q., Levine, E.L., Smith, M.A., Ispas, D., \& Rossi, M.E. (2008). Person-environment fit or person plus environment: A meta-analysis of studies using polynomial regression analysis. Human Resource Management Review, 18, 311-321.

Zhang, Y., Xu, S., Jin, J., \& Ford, M.T. (2018). The within and cross domain effects of work-family enrichment: A meta-analysis. Journal of Vocational Behavior, 104, 210-227. 


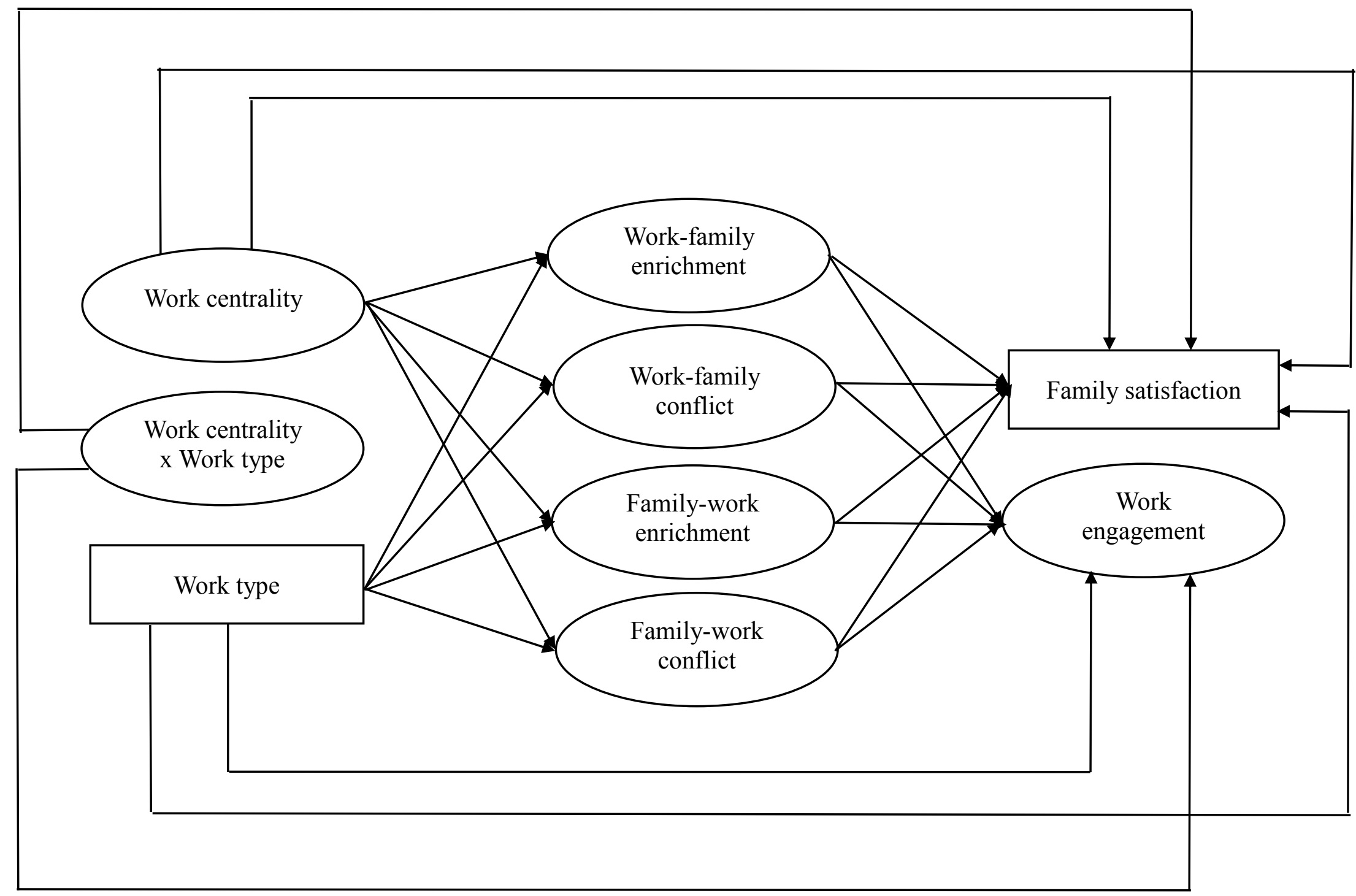

Figure 1. Theoretical model 


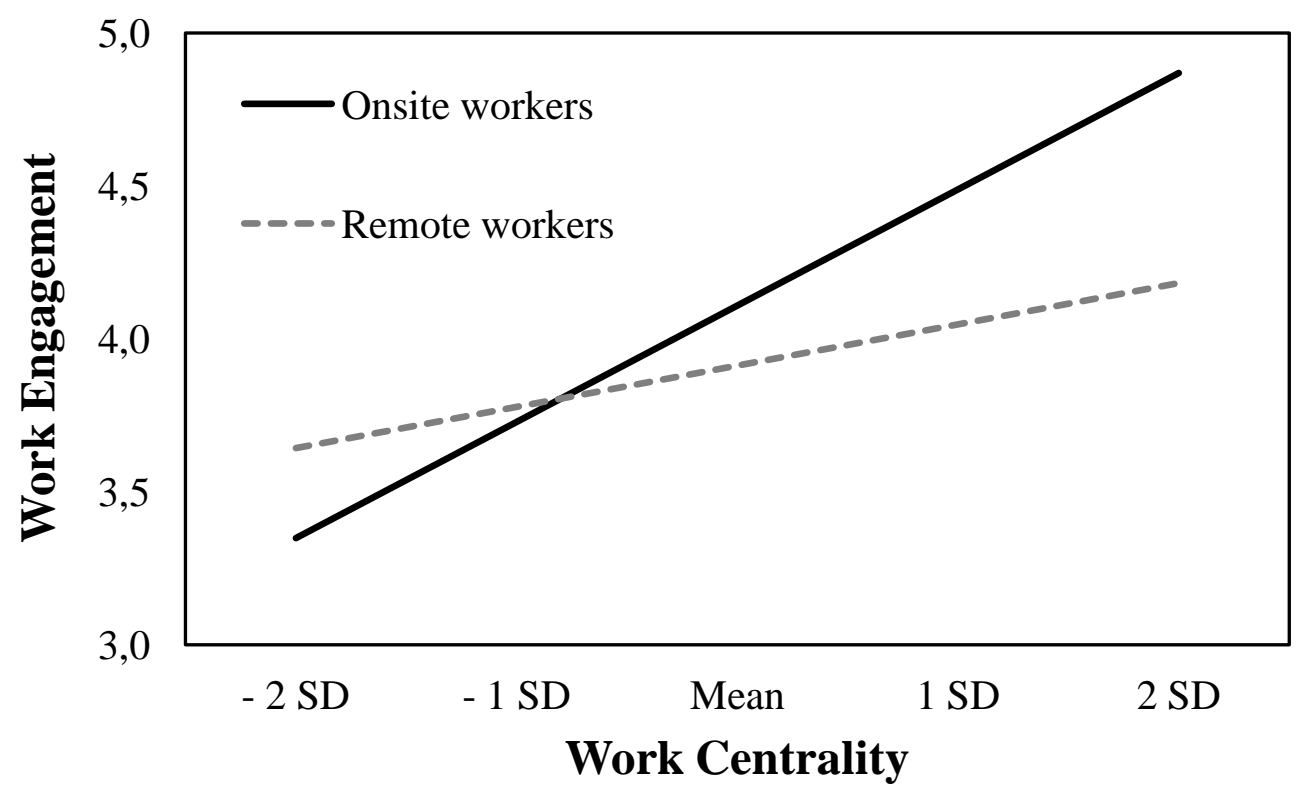

Figure 2. Simple slope analysis of the effects of work centrality on work engagement among onsite and remote workers

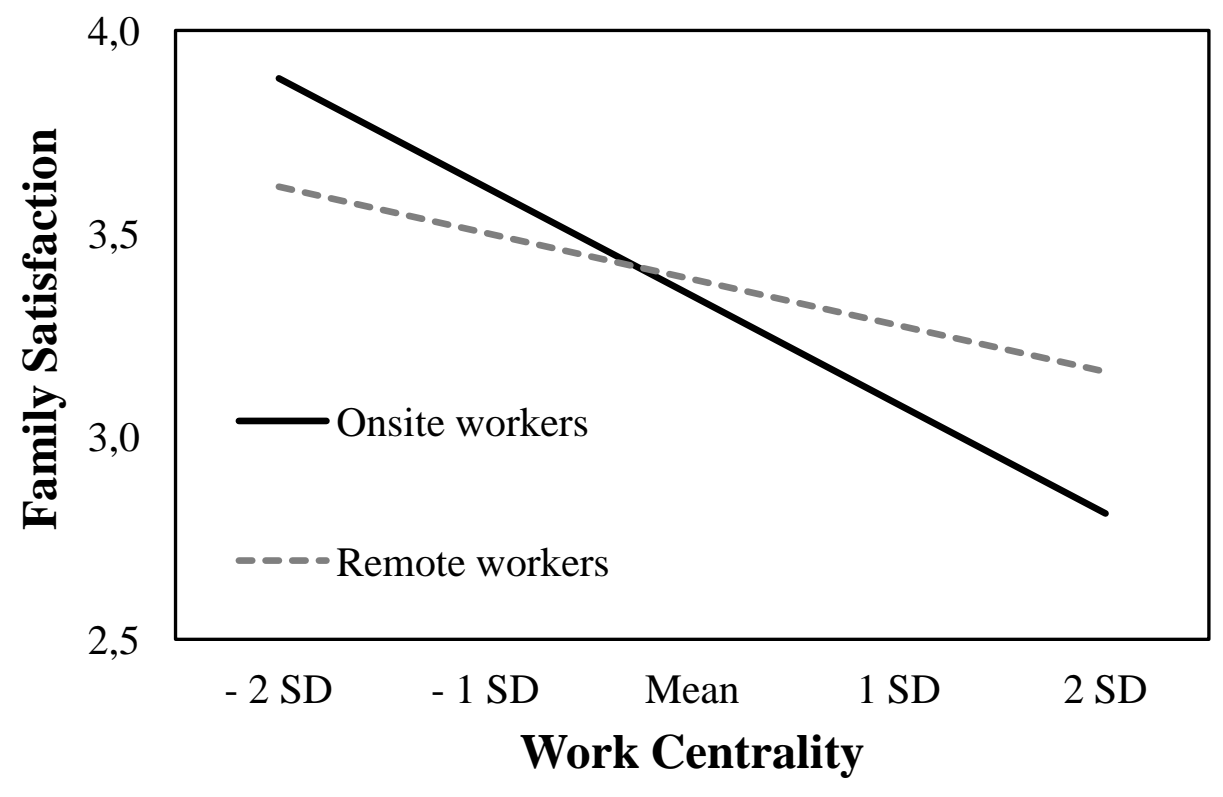

Figure 3. Simple slope analysis of the effects of work centrality on family satisfaction among onsite and remote workers 
Table 1

Standardized Factor Loadings $(\lambda)$ and Uniquenesses $(\delta)$ from the Confirmatory Factor Analytic Solution

\begin{tabular}{|c|c|c|c|c|c|c|c|}
\hline Items & $\begin{array}{c}\text { Work } \\
\text { centrality } \\
\lambda\end{array}$ & $\begin{array}{c}\text { WFC } \\
\lambda\end{array}$ & $\begin{array}{c}\text { FWC } \\
\lambda\end{array}$ & $\begin{array}{c}\text { WFE } \\
\lambda\end{array}$ & $\begin{array}{c}\text { FWE } \\
\lambda\end{array}$ & $\begin{array}{c}\text { Work } \\
\text { engagement } \\
\lambda\end{array}$ & $\delta$ \\
\hline \multicolumn{8}{|c|}{ Work centrality } \\
\hline Item 1 & .694 & & & & & & .518 \\
\hline Item 2 & .894 & & & & & & .201 \\
\hline Item 3 & .907 & & & & & & .177 \\
\hline Item 4 & .783 & & & & & & .387 \\
\hline Item 5 & .874 & & & & & & .236 \\
\hline$\omega$ & .919 & & & & & & \\
\hline \multicolumn{8}{|l|}{ WFC } \\
\hline Item 1 & & .932 & & & & & .131 \\
\hline Item 2 & & .961 & & & & & .077 \\
\hline Item 3 & & .930 & & & & & .136 \\
\hline Item 4 & & .921 & & & & & .152 \\
\hline Item 5 & & .821 & & & & & .325 \\
\hline$\omega$ & & .962 & & & & & \\
\hline \multicolumn{8}{|l|}{ FWC } \\
\hline Item 1 & & & .833 & & & & .306 \\
\hline Item 2 & & & .832 & & & & .308 \\
\hline Item 3 & & & .861 & & & & .258 \\
\hline Item 4 & & & .856 & & & & .267 \\
\hline Item 5 & & & .865 & & & & .252 \\
\hline$\omega$ & & & .928 & & & & \\
\hline \multicolumn{8}{|l|}{ WFE } \\
\hline Item 1 & & & & .762 & & & .420 \\
\hline Item 2 & & & & .941 & & & .114 \\
\hline Item 3 & & & & .920 & & & .153 \\
\hline$\omega$ & & & & .909 & & & \\
\hline \multicolumn{8}{|l|}{ FWE } \\
\hline Item 1 & & & & & .718 & & .484 \\
\hline Item 2 & & & & & .825 & & .320 \\
\hline Item 3 & & & & & .883 & & .220 \\
\hline$\omega$ & & & & & .852 & & \\
\hline \multicolumn{8}{|c|}{ Work engagement } \\
\hline Item 1 & & & & & & .803 & .355 \\
\hline Item 2 & & & & & & .920 & .153 \\
\hline Item 3 & & & & & & .808 & .347 \\
\hline$\omega$ & & & & & & .882 & \\
\hline
\end{tabular}

Note. WFC: Work-family conflict; FWC: Family-work conflict; WFE: Work-family enrichment; FWE: Family-work enrichment; $\lambda$ : Factor loading; $\delta$ : Item uniqueness; $\omega$ : Omega coefficient of model-based composite reliability; all parameters are significant $(\mathrm{p} \leq .01)$. 
Table 2

Latent Correlations from the Confirmatory Factor Analytic Solution

\begin{tabular}{|c|c|c|c|c|c|c|c|c|}
\hline Variable & 1 & 2 & 3 & 4 & 5 & 6 & 7 & \\
\hline 1. Work centrality & - & & & & & & & \\
\hline 2. Work-family conflict & $.215^{* *}$ & - & & & & & & \\
\hline 3. Family-work conflict & $.241 * *$ & $.489 * *$ & - & & & & & \\
\hline 4. Work-family enrichment & $.237 * *$ & $-.117 *$ & .022 & - & & & & \\
\hline 5. Family-work enrichment & $-.134 *$ & -.017 & -.074 & $.534 * *$ & - & & & \\
\hline 6. Work engagement & $.271 * *$ & -.054 & .003 & $.681 * *$ & $.346^{* *}$ & - & & \\
\hline 7. Family satisfaction & $-.224 * *$ & $-.136 * *$ & $-.235 * *$ & $.219 * *$ & $.279 * *$ & $.238 * *$ & - & \\
\hline 8. Work type (onsite vs. remote) & $.101 *$ & .004 & $.137 * *$ & .015 & .003 & -.035 & -.002 & - \\
\hline
\end{tabular}

Note. $* \mathrm{p} \leq .05, * * \mathrm{p} \leq .01$. 


\section{Table 3}

Predictive Results

\begin{tabular}{|c|c|c|c|c|c|c|c|c|c|c|}
\hline \multirow[b]{2}{*}{ Predictors } & \multicolumn{2}{|c|}{ Work engagement } & Family satisfaction & \multirow{2}{*}{$\begin{array}{l}\text { WFC } \\
\text { b (s.e.) }\end{array}$} & \multirow[b]{2}{*}{$\beta$} & \multirow{2}{*}{$\begin{array}{l}\text { FWC } \\
\text { b (s.e.) }\end{array}$} & \multirow{2}{*}{$\begin{array}{l}\text { WFE } \\
\text { b (s.e.) }\end{array}$} & \multirow[b]{2}{*}{$\beta$} & \multirow{2}{*}{$\begin{array}{l}\text { FWE } \\
\text { b (s.e.) }\end{array}$} & \multirow[b]{2}{*}{$\beta$} \\
\hline & b (s.e.) & $\beta$ & b (s.e.) & & & & & & & \\
\hline \multicolumn{11}{|c|}{ Basic Predictive Model } \\
\hline Work centrality & $.203(.073) * *$ & .149 & $-.158(.039) * *-.221$ & $.227(.055)^{*}$ & .221 & $.246(.066)^{* *}$ & $.237 .236(.057)^{* * *}$ & .230 & $-.131(.056)^{*}$ & -.129 \\
\hline Work type & $-.148(.116)$ & -.052 & $.064(.069)$ & $-.035(.107)$ & -.017 & $.249(.101)^{*}$ & $.115-.021(.109)$ & -.010 & $.030(.112)$ & .014 \\
\hline WFC & $-.002(.063)$ & -.002 & $.018(.042)$ & & & & & & & \\
\hline FWC & $-.048(.061)$ & -.037 & $-.136(.044)^{* *}-.197$ & & & & & & & \\
\hline WFE & $.836(.088)^{* *}$ & .630 & $.150(.045)^{* *} .216$ & & & & & & & \\
\hline FWE & $.078(.077)$ & .057 & $.096(.050)^{\dagger} \quad .135$ & & & & & & & \\
\hline $\mathrm{R}^{2}$ & $.462(.046)^{* *}$ & & $.152(.036)^{* *}$ & $.049(.023)^{*}$ & & $.069(.030)^{*}$ & $.053(.024)^{*}$ & & $.017(.014)$ & \\
\hline \multicolumn{11}{|c|}{ Predictive Model with Latent Interactions } \\
\hline Work centrality & $.380(.102)^{* *}$ & .275 & $-.268(.057)^{* *}-.374$ & $.369(.085)^{*}$ & .221 & $.308(.080)^{* *}$ & $.237 .185(.043)^{* * *}$ & .231 & $-.091(.039)^{*}$ & -.129 \\
\hline Work type & $-.167(.116)$ & -.058 & $.076(.069) \quad .051$ & $-.058(.174)$ & -.016 & $.313(.128)^{*}$ & $.115-.017(.085)$ & -.010 & .021 & .014 \\
\hline WFC & $.003(.039)$ & .004 & $.009(.026)$ & & & & & & & \\
\hline FWC & $-.039(.048)$ & -.037 & $-.109(.034) * *-.197$ & & & & & & & \\
\hline WFE & $1.090(.125)^{* *}$ & .631 & $.188(.059)^{* *} .210$ & & & & & & & \\
\hline FWE & $.109(.113)$ & .055 & $.138(.072)^{\dagger} \quad .136$ & & & & & & & \\
\hline Centrality x Design & $-.245(.120)^{*}$ & -.085 & $.154(.069) * \quad .103$ & & & & & & & \\
\hline \multirow[t]{2}{*}{$R^{2}$} & $.478(.045)^{* *}$ & & $.168(.037)^{* *}$ & $.049(.023)^{*}$ & & $.069(.030)^{*}$ & $.053(.024)^{*}$ & & $.017(.014)$ & \\
\hline & A & b (s.e.) & b (s.e.) & & & & & & & \\
\hline
\end{tabular}

Work centrality: Simple Slope Analyses

\begin{tabular}{|c|c|}
\hline workers & 4.109 \\
\hline & 3.91 \\
\hline
\end{tabular}

Note. WFC: Work-family conflict; FWC: Family-work conflict; WFE: Work-family enrichment; FWE: Family-work enrichment; Work type: $0=$ Onsite workers and $1=$ Remote workers; $\mathrm{R}^{2}$ : Squared multiple correlation (reflecting the proportion of explained variance); a: Regression intercept (used in drawing the simple slope graphs); b:

Unstandardized coefficient; s.e.: Standard error of the coefficient; $\beta$ : Standardized coefficient; $\dagger p=.055, * p \leq .01, * * p \leq .01$. 